\title{
Communities of Practice: The Way Forward to a Sustainable Development in the 21st Century? An Open Distance eLearning Perspective
}

\author{
Prof. A. Coleman ${ }^{1}$ and Dr. A. Giannakopoulos ${ }^{2}$
}

\begin{abstract}
Living in a knowledge era, the production of new knowledge through innovation and sharing of knowledge, especially tacit knowledge, have become two prerequisites for the sustainability of any organisation. The days of 'knowledge is power' is slowly fading away and is replaced by 'knowledge sharing is power'. Sharing of knowledge under voluntary conditions among people forms the essence of a Community of Practice (CoP). The days of the 'ivory tower' are gone. If the institution's approach to knowledge is one of 'knowledge is power' it will not lead to its sustainability as other competitors will seize the competitive advantage through innovation by sharing knowledge among its academics. A number of authors agree that education is the key to sustainable development. This paper explores the use of CoPs at a university as a means to decrease attrition and thus contribute to its sustainability and a model is proposed.
\end{abstract}

Keywords - Communities of Practice, Sustainability, Higher Education, Sustainable Development

\section{INTRODUCTION}

Higher learning (HL) traditional institutions in general and Open Distance eLearning (ODeL) institutions in particular in the 21 st century are faced with challenges that did not exist a decade or two ago. 'Publish or parish', low student graduation rates, demands for free education, competition for high caliber students and academics, increasing costs and student debt are just a few challenges that if action is not taken sooner than later they can lead to their extinction. The days of the 'ivory tower' have gone. Reactive action can be too late to stop the 'downhill run'. Aiming for becoming just a research institution, although it is a prerequisite for a HL institution, it is not sufficient. Research cannot be dissociated from graduation rates as irrespective of excellence in research, low graduation rates will minimise the impact of such research. Therefore, an HL institution cannot sustain itself just from excellence in research. McKeown's [1] statement that education is the key to sustainable development is accepted here as the unit of analysis. Such development is closely related to Communities of Practice (CoPs) among other factors, even at a HL institution.

\section{ConteXt And Rationale Of The Study}

This study concerns an Open Distance Learning (eLearning)

Prof. A. Coleman, University of South Africa, South.

Dr. A. Giannakopoulos, University of South Africa, South Africa
(ODL, ODeL) institution, Unisa (University of Soth Africa). It is the second largest ODL institution in the Common wealth countries, with approximately 400000 students, national and international. It has been growing for the past 10 years by about an average of $8 \%$ and in 2016 by $5 \%$. In order to explore Communities of practice in an HL institution, it is necessary to develop a rationale. At the heart of any HL institution is graduation rates (the quantitative aspect) and the caliber of student produced (the qualitative aspect). Both need to be managed in an efficient way. Graduation rates are related to student retention, the institutional aim, and persistence to graduate, a student's aim [2]. Obviously although institution and student aim for the same thing, graduation, the means to achieve this end differ. The problem of attrition has been considered as a wicked problem by [3]. Such a problem has no clear immediate solution and normal problem solving methods are not applicable. Therefore a partial solution could minimise the impact of the problem. In this case if attrition rates at ODL institutions have been around $75 \%$ decreasing it by even a $5 \%$ it can have great positive impact on the institution.

Attrition rates have an impact on economics as well as the status [4],[5] of the institution. Both, unless improved could lead to non-sustainability of the institution. With respect to economics the ideal situation is a $100 \%$ graduation rate. That is the number of students entering the institution for the first time must be equal to the number that graduate, but at the minimum time. What tends to happen is that many students persist and graduate but it can take anything from one year to even seven extra years. This extra time is part of the wastage of resources. On the other hand low attrition rates and quality of the graduate impact on the status of the institution. But sustainability of HE is also depending not only on quantity (higher graduation rates) but also on the quality of the product, the graduate [6]. Research has shown that quantity can have a negative effect on quality of education, especially if the standards are dropped. If the institution accepts low caliber students that leads to low status institution. To move back to high status more often than not, is an impossibility [7].

While many models have been designed to decrease attrition rates since the late ' 80 s [8], [9] and some were modified by others [10] the attrition rates remain relatively high. For an ODL [11] for Unisa, will be used in this study as it forms an addition to that model. The wickedness of the problem requires creative and innovative ways. In this case knowledge management is 
used as the means to sustainability of the institution. And Communities of Practice (CoPs) are at the heart of the organisation's retention and creation of knowledge and innovation and thus of a competitive advantage [12]. There is very little research done on this subject, perhaps due to the fact that for an HL the three aspects of knowledge, retention, transmission, and creation of knowledge form the focus of an HL institution and contribute to its sustainability. It then can be argued that applying knowledge management principles in a HL institution has to be approached in a different way than when applied in other private enterprises since academics are the agents of those three knowledge aspects.

Accepting that the sustainability of a HL institution is dependent on graduation rates, retention, transmission and creation of knowledge and quality of graduates, it will be argued that formation of CoPs among the various role players (academics, students, institution) it could minimise the attrition rates and improve on the quality of the graduate could lead to a competitive advantage and thus its sustainability. Giannakopoulos and Buckley [13], [14] previous works and other literature will form the basis of this paper. First, it is necessary to discuss briefly sustainable development in order to form the basis for sustainability. This is followed by a discussion on the reasons for existence of HL institutions and especially ODL institutions. Since knowledge management (KM) principles are applied here then the connection between $\mathrm{KM}$ and sustainability is discussed. Finally, since CoPs are used to gain a competitive advantage and thus sustainability, a model is proposed as to how can such CoPs will be formed and applied in practice.

\section{A. Sustainable development}

Sustainable development was initially introduced by the Brundtland Commission in its 1987 report. It is an organizing principle for human life on a finite planet. It posits a desirable future state for human societies in which living conditions and resource-use meet human needs without undermining the sustainability of natural systems and the environment, so that future generations may also have their needs met [15]. The commission defined sustainable development as development that meets the needs of the present without compromising the ability of future generations to meet their own needs [15].

The concept sustainability has in the past most often been broken out into three constituent domains: environmental (ecological), economic and social (cultural and political) sustainability, the known circles of sustainability. The sustainability paradigm rejects the contention that casualties in the environmental and social realms are inevitable and acceptable consequences of economic development [1]. "Sustainability can be considered to be a "paradigm for thinking about a future in which environmental, societal, and economic considerations are balanced in the pursuit of development and improved quality of life" [1]. With respect to sustainability of HL institutions it is aimed at sustaining itself and making contributions towards sustainability of the human kind (the social aspect). A HL institution can be considered as a microcosm. Economics and quality of the product (a graduate) form the 'fuel' of such microcosm. Using this assumption, sustainability is defined as the continuous existence of an $\mathrm{HL}$ institution, with no debt (economically viable, living on the interest rather than on the principle), by maintaining high educational standards and the student graduation rate growth to be equal if not greater than the student population rate growth [1]. By producing graduates for different fields they in turn make a contribution to the sustainability of the country [14]. Education is an essential tool for achieving sustainability [1].

McKeown [1] also argues education is not only a means to human well-being for a controlled population growth (sustainability), but also highly educated people, who have higher incomes, consume more resources (non-sustainability) than poorly educated people.

\section{B. Universities as generators, retainers and transmitters of knowledge}

Universities had come to existence to serve the human kind as forces of economic growth, by taking charge of existing knowledge in various fields and retain it; transmit it to young students so one day they can also make contributions to humanity; and create new knowledge. At the same time empower these students and instill in them values of the society and develop in them skills such as problem solving and critical thinking. The way such knowledge and skills are imparted become one of the numerous factors that give rise to attrition [17], [8], [9]. Wick et al. [19] claim that one way to ensure sustainability is to ensure that graduates possess certain key competencies The authors propose to employ competencies as a references scheme for evaluation of student learning and teaching effectiveness. Competency in this view is a "functionally linked complex of knowledge, skills and attitudes that enable successful task performance and problem solving." In a knowledge era, universities are not excluded from applying appropriate knowledge management principles for their growth, sustainability and competitive advantage.

The progress in ICT (Information Communication Technologies) have made ODL and traditional contact universities less distinct [18]. As a result, nowadays these two types of institutions compete in the market for the same number of students. While ODL institutions are predominantly distance traditional universities are predominantly face to face. Each one has its own advantages and disadvantages. In many cases the one's disadvantage is the other's advantage. The most important ones could be, but not limited to: availability of physical space (there are constraints in face to face); time of delivery (face to face is bound by fixed times of lecture deliver and so on thus synchronous delivery); tuition fees (as a rule are higher for face to face); face to face could be considered as a preferred way of communicating compared to virtual way; lack of face to face socialisation (in ODL students are on their own thus feeling isolated). These few differences could give rise also to a competitive advantage.

Since one of the core business of the university is the retention, transmission and creation of new knowledge then 
since they are also some of the core business of KM then it is necessary to examine KM in a university set up.

\section{Knowledge management in universities and sustainability}

If it is accepted that knowledge is the key to success and sustainability then in a higher education institution where its main functions are, retention, transmission and creation of new knowledge has to have systems in place to guarantee the maintenance of these functions [13]. These de facto functions are the ingredients of Knowledge Based Development [16]. The White Paper on higher education adds that universities" must provide opportunities for social mobility and strengthen social justice and democracy, thus helping to overcome the inequalities inherited from our apartheid past" [19]. Knowledge that is possessed by academics and other staff needs to be managed. It does not help to aim for high caliber of academics if they cannot be retained. Giannakopoulos and Buckley [13] go as far as to say that the sustainability and the power of a HE institution are determined to a large extent by, and measured against, the extent to which staff are obtained, developed, managed and retained [20]. Pienaar and Bester [20] and Smith [21] who see the recruitment and retention of new academics, especially of high caliber, to be challenging as academics are moving out to other fields for better job opportunities.

Majewski et al. [6] state that KM based systems can be used to a great extent for sustainability of HE. But achieving sustainability in HE in a rising economy such as South Africa is not always an easy feat. There are a number of factors that need to be taken into account. Some of these factors come from the environment of an organizational institution (e.g. government, society, and economics) and some come from the internal mechanisms (e.g. internal policy, funding and organizational structure). As stated earlier by [17], if graduation rates are one of the factors for sustainability (quantity) and if the type of graduate (quality) is another together with research outputs then one way to ensure sustainability is to ensure that graduates possess certain key competencies.

Majewski et al. [6] provide two basic definitions of KM and note that the two have in common a structured approach to knowledge assets. Based on that he states that any structured activity, which improves an organization's capacity to acquire, share and use knowledge in the ways that improves its survival and success should be part of KM systems. In this view it is possible to see common interest between KM strategy and sustainability strategy, which is long-term existence and success and all $\mathrm{KM}$ activities.

This takes us to the last aspect of the paper which is the role of CoPs as a way of developing a system KM based sustainability.

\section{COMmunities Of Practice}

Briefly the idea of CoPs were initially introduced by [22]. Wegner and Snyder [23] defined a CoP as "a group of people informally bound together by shared expertise and passion for a joint enterprise." A CoP is a model of situational learning, based on collaboration among peers, where individuals work for a common purpose defined by knowledge and not by task [24]. One thing that literature has not emphasised enough is the word 'passion'. Passion begins where the brain stops. It leads to inspiration for innovation. Make a difference. For more on CoPs the reader can consult [25]-[27] to name just a few though the number of papers written about CoPs are almost inexhaustible.

The most important thing here is that although the original idea of CoPs contained the words 'informally created' and 'voluntary' the later has remained but the former was changed in certain situations to 'formally created', initiated by a champion or even the organisation. The second important point is what [22] call Legitimate peripheral Participation (LPP). Such participation could be compared with the Zone of Proximal Development (ZPD) of [28]. ZPD is could be considered as knowledge that carries uncertainty. It has not yet become part of the knowledge structure of the individual. When people collaborate then their core knowledge and ZPD interact and gives rise to gain in knowledge by the participants. It is a kind of 'two brains are better than one'.

Saint-Onge and Wallace [12] distinguished between informal supported and structured types of CoPs. The informal community of practice is self-joining, without organizational sponsor, very organic, and so natural that it may not even be noticed. Still this type of community is based on the discussion forums for knowledge creation and sharing which assists them with their work. Supported and structured CoPs are characterized by more intense involvement of the host organization. The competency building of such a CoP is aligned with the strategic purpose of host organization and monitoring of the management is present. It can be argued that if there is such intense involvement of and monitoring by management in the end it could become a barrier and affect the value of the CoP in knowledge creation and sharing. Such problem could be alleviated if the members view their participation as a way of self-improvement and by default the company benefits.

However since the inception of CoPs by [22] the progress in technology created limitations in the application of CoPs in a work place which is faced with complex situation which become barriers into CoPs formation. For Wegner and McDermott [29] in higher education it is important to understand the role of social learning from group work by students, lecturers and institution. Group work has been accepted as a way of problem solving, transfer of skills necessary for work place. As learning is becoming more student centered then the student assumes more responsibility for his/ her learning. Group projects, if properly managed provide a forum for experiential and collaborative learning. The student is no longer a passive participant. Becoming engaged with learning has been recognised as one of the factors for academic success.

Saint-Onge and Wallace [12] characterised the members of a $\mathrm{CoP}$ according to their participation. They identified the sparkers or debate triggers, synthesizers or summarizers, sole contributors who contribute from their own perspective and witnesses who support a position with their own point-of-view or experience. Then the champions who are the most powerful 
members of a community and "lurkers" - people who do not contribute to the community but who take from it what they can. In a $\mathrm{CoP}$ one gets, the founders and coordinators, the associate members and the legitimate peripheral group [30]. The peripheral group is fluid, and depends on the discussion topics. Pavlin [30] found that there is a strong connection between participation in the discussion and attendance; people who substantially contribute to the discussion are also regular guests and vice versa. For Pavlin, the coordinator who is similar to [12] champion, occupies the crucial role in a community. He plans the activities, balances and energizes community events, and facilitates discussion and knowledge sharing. This coordinator/ champion is most of the time one of the experts. It is also possible that others are involved indirectly who do not participate in the $\mathrm{CoP}$ but could be sponsoring/ supporting the CoPs activities, such as top managements who according to [30] they navigate and initiate the very existence of a community towards strategic goals of the organization by providing necessary resources such as time, basic funding and legitimacy within organization. They do not manage community's knowledge, but they indirectly manage, facilitate and sometimes even create CoP.

As knowledge sharing is one of the core business of CoPs, Kasemsap [33] identified lack of time, lack of trust and poor communication skills, lack of technology or lack of resources, lack of knowledge transfer mechanisms as barriers to knowledge sharing. As most of the time CoPs might operate after working hours, employees could be reluctant to put that extra time. Perhaps Lave and Wenger [22] were aware of that and that is why passion was included as a precondition for the success of a CoP. Trust is a prerequisite for knowledge sharing since it builds social relationships. Knowledge transfer is directly related to collaborative communication practices. In an ODL system especially where technology is the main means of communication could be another barrier if it is not reliable or there is a lack of up-to-date technology. For example in a case where a department is supposed to be the leader in nanotechnology, lack of up-to-date technology can have a negative impact on the performance of the lecturer. Using technology could remove some perceptions of people. In South Africa for example where racism still exists among some people, using technology removes the barrier of colour.

Monaghan and Columbro [32] suggested a four stage model for formation of CoPs. The formation, the implementation, the reflection and the sharing stage. In each of these stages certain tasks are assigned. In the first stage the scene is set for deciding on the topic, devise a learning plan and get to know each other. In the second stage the plan is implemented and each student facilitates a session. In the third stage formation, implementation and sharing knowledge stages and reflect on activities. In the final stage knowledge sharing takes place between the various CoPs.

Pavlin [30] found that formal departments, operational and project teams within an organization seem to become insufficient for prosperous creation, dissemination and utilization of knowledge.

In the South African context, the importance of CoPs is highlighted in a document by the National Research Foundation (NRF), a government funded department that evaluates research, classifies researchers into categories and also funds important research projects. What the document highlights about CoPs is that CoPs "provide a vehicle to enable the implementation of integrated trans-disciplinary and multi-disciplinary solutions" to address various challenges such as HIV aids, poverty, social injustices, education and training to name just a few [33]. Such solutions to be research based. The proposed model here is in line with this statement as the ultimate aim is to use CoPs in an inter-disciplinary and multi-disciplinary way to improve graduation rates through Action Research. [33] defines CoPs as "research-led alliances, in which established researchers collaborate to produce solution-oriented research findings with an intention to translate research outputs into tangible outcomes and influence policy development and implementation through communication of the necessary findings."

With respect to online or virtual CoPs [34] found that in virtual CoPs members will be less hesitant to post information on the CoP site if the can trust that their confidatial information won't be misused and that the source of information on the site is reliable (trust is involved). That trust could be knowledge based in the participants interactions. If the online communities were the result of face to face communities, then it will be easier to trust the members of the $\mathrm{CoP}$. Integrity and competence are ranked high when it comes to trust. Ardichvili et al. [34] found also that some times one can get new information or advice from weak ties, people we do not know much than from those we know. If a CoP starts with a group of strangers then the trust is not on the individual but in the whole social entity.

\section{A. Communities of Practice at Unisa}

In an ODL institution such as Unisa which has a central campus and two auxiliary campuses (the science and another administrative) and more than 10000 people work there where about 2000 are academics, starting CoPs can be very challenging at least for two reasons: The spread of academics and attitudes of academics towards collaborative research. The former one can argue should not be a problem as technology can become the medium of communication. The latter's impact could be minimised by the word 'voluntary participation'. Cheng and Lee [35] states that it is not easy to impose or create a Cop as according to Wegner and McDermott [36] a CoP can only be coordinated, facilitated and cultivated. Tight [37] also speaks of CoP and content facilitation. A CoP could be used for content and process of knowledge sharing. Content facilitation focuses on the needs of the $\mathrm{CoP}$ members especially in activities that the members work together. Content facilitation guides the content of the dialogues to ensure that they are in line with the knowledge domain of the joint enterprise [37]. But as CoPs are accepted as a way of knowledge sharing and creating knowledge, then certain strategies can be employed to initiate a $\mathrm{CoP}$ other than the one that is formed informally by people. [37] 
says CoP can emerge from bottom-up initiatives but this does not mean that organizations cannot influence their development. In fact, more and more CoPs are initiated by a sponsor at the senior management level, rather than emerging spontaneously [38].

CoPs could also be started by a champion [12], [35] as stated ealier, who could be part of management or an employee at any level of the organisational structure [35]. The writer was such a champion for Unisa. However, it was necessary to identify a common goal. In order to start CoPs in such an environment, they could have been initiated by management or by a champion [12], [35]. But then 'a

common goal' had to be identified. The writer, having studied the problem of attrition for about three decad its own particular domain and therefore some particular $\mathrm{T} \& \mathrm{~L}$ strategies. In addition to that, it has been accepted by the members of the various CoPs that Action Research (improve practice through research) into $\mathrm{T} \& \mathrm{~L}$ will be applied. Such research will be formalised and published in journals or presented in conferences. This gives rise to research output. At the same time, academics that do specialised research will continue with that.

The foundation of the CoPs here lies on: The academic's role which should be one of a diagnostic action researcher; [11] model of student success in an ODL and [13] sustainability model for an ODL institution. As a result, a Project 2020 was initiated which is a longitudinal study (5 years duration), into the academic success. The rationale was that the teaching and learning ( $\mathrm{T} \& \mathrm{~L}$ ) of all subjects affect success rates. Therefore, ODL strategies in T \& L can be common. Then each subject has Using this rationale the writer championed the project. He identified the Directors and heads of departments of some colleges as the possible champions for their respective Schools or departments. The writer then presented the project to these colleges and a CoP was formed between the writer and them. As the writer is a specialist in education and research, then the members' role in the newly formed CoP interchange between a 'novice' and an 'expert'. So far eight CoPs have been formed and the writer has bi-weekly has meetings with them and advice is given how to use research in their particular subjects. At the School of Computing another CoP was formed among all the programmers as programming has been identified as a subject with the least past rates. Fig. 1 illustrates the structure, a web of CoPs, sharing the same goal (decreasing attrition) which is one of the most important factors that contributes to the sustainability of the institution. The units of analysis are student, lecturer and institution. Engagement (between institution, lecturer and student) and investigating the types of knowledge possessed by students, form the basis of the research. Research [39], [40] has shown that student engagement is one of the prerequisite to persistence. The types of knowledge also play a central role [41] for academic success. Each lecturer (the member of the $\mathrm{CoP}$ ) will venture into general $\mathrm{T} \& \mathrm{~L}$ research and in particular in his/ her subject.

Lecturers can be trained to involve students in forming CoPs rather than allocating them randomly into study groups. The idea of [34] can be used and bear in mind the six success factors of CoPs: that they identified, organization, optimizing interactions, infrastructure, supporting tools, strategy and goals, and organizational support.

And a successful $\mathrm{CoP}$ leads to knowledge creation and sharing of tacit knowledge. Universities should take note of that and attempt to develop ways and means to encourage and promote the formation of CoPs among the students where the lecturer could be the facilitator. This should not be confused with just a random allocation of students to a group. It has not be noted that there is no conclusive evidence as to grouping students to a CoP randomly or using certain criteria. It is true though that sometimes the lecturer's teaching style could also be a barrier when teacher centered and decontextualised procedural practices predominate .

For Fearon et al. [29] in higher education it is important to understand the role of social learning from group work by students, lecturers and institution. Group work has been accepted as a way of problem solving, transfer of skills necessary for work place. As learning is becoming more student centered then the student assumes more responsibility for his/ her learning. Group projects, if properly managed provide a forum for experiential and collaborative learning. The student is no longer a passive participant. Becoming engaged with learning has been recognised as one of the factors for academic success. Wenger et al. [36] also found that CoPs can increase the likelihood that students will find their own voice and niche within a particular discipline [36]. The result for learners is a stronger connection to the material because they are able to self-direct and self- select areas of interest that are most relevant to their lives.

The various champions, the experts, will monitor the progress of their CoPs and such progress will be uploaded in a common database of which everybody will have access to. Then once a month the $\mathrm{CoP}$ of the champions will take place and problems that could have encountered will be dealt with. The modus operandi of the CoPs will be determined by each CoP. For example it could be a virtual one, face to face or combination of both.

\section{CONCLUSION}

ODL education has come a long way since its inception. Initially was serving adult students, most of them working, and who wanted to improve their qualifications. Normal post was used and it started as education through correspondence. But as technology progressed less distinction could be made between traditional contact institutions an ODL institutions. For various reasons either type of institution introduced functions of the other. The face to face begun to use online delivery while ODL institutions used face to face time and again. Both types of education delivery have their advantages and disadvantages and technology on the one hand and quality of education and service delivery on the other have become issues of concern as they both lead to a competitive advantage. Both types of institutions 
are plagued by the same problem and that is low graduation rates, though ODL institutions do have lower graduation rates.

For the institutions to sustain themselves economics and status play a central role. As government subsidies declined, HL institutions could not just increase the fees. On the contrary students not only are not prepared to pay for the increases (especially in South Africa since 2015), but demand free education. Amidst these could lead to graduation. One way to achieve this is through Co problems the institutions need to develop strategies which should only lead to student retention but also to student persistence which

communities of Practice among the academics and the students. There is sufficient evidence that Communities of
Practice do lead to knowledge creation and transmission (through sharing) especially of the tacit knowledge. If application of CoPs is successful it could increase graduation rates and thus could lead to a competitive advantage and thus guarantee the sustainability of the institution.

A model for formation of Communities of Practice was proposed which has been established at Unisa and is operational, by the writer. Since it is only one year old, it is not possible to evaluate its effectiveness but what can be said in a nut shell by the writer who championed the project, use of a champion who is passionate and expert about a chosen common goal among the academics, is most probably the way to go about in establishing CoPs at an ODL.

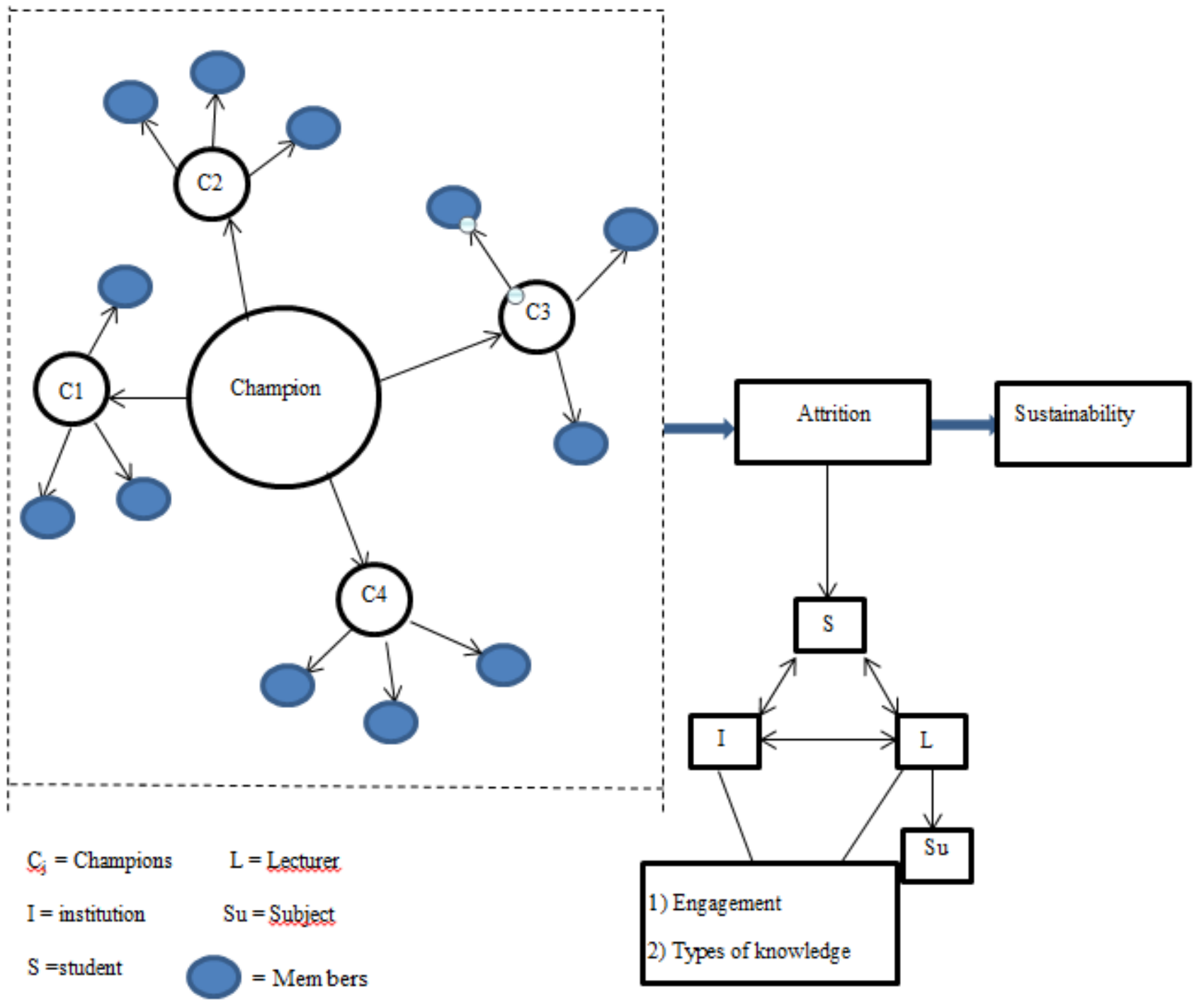

Fig. 1: A model of Communities of Practice at Unisa

[2] V. Tinto, "From retention to persistence." Available at: https://www.insidehighered.com>views. 2016

\section{REFERENCES}

[1] R. McKeown, "Education for Sustainable Development Toolkit." Available: : http://www.esdtoolkit.org/esd_toolkit_v2.p . 2002.
[3] C. Beer and C. Lawson, "The problem of student attrition in higher education: An alternative perspective." Available at: http://dx.doi.org/10.1080/0309877X.2016.1177171 [10/02/2017, 2017]. 2016.

[4] Sapa. "University dropouts increase." Available at: http://news.iafrica.com/sa/917608.htm. 2008. 
[5] J.P. Bean, "Student attrition, intentions and confidence: Interaction effects in a path model." Research in Higher Education, vol 17, no. 4, pp 291-320. 1982. https://doi.org/10.1007/BF00977899

[6] G. Majewski, S.B. Buckley and Giannakopoulos, "Achieving a sustainable growth in HE institution through knowledge-based strategies: A rising economy perspective." Presented at IFKAD 2014 Conference, Italy, 11-13 June 2014

[7] S. Macrae and M. Maguire. (2002). "Getting in and getting on: Choosing the best." in Access, participation and higher education: Policy and practice, A. Hayton and A. Paczuska, E. pp 168-189. London: Biddles Ltd, 2002, pp 168-189.

[8] V. Tinto, Leaving college: Rethinking the causes and cures of student attrition, 2nd ed, Chicago: University of Chicago Press. 2003

[9] A.W. Astin, What matters in college? Four critical years revisited, San Francisco: Jossey-Bass Inc. 1993

[10] R. Sweet, "Student Dropout in Distance Education: An Application of Tinto's Model. Distance Education, vol 7, no. 2, pp. 201-213, 1986 https://doi.org/10.1080/0158791860070204

[11] P. Prinsloo, "Modelling throughput at Unisa: A key to successful implementation of ODL." DISA, UNISA. 2009

[12] H. Saint-Onge and D, Wallace, Leveraging Communities of Practice for strategic advantage. Burlington, MA: Butterworth-Heinemann. 2003.

[13] A. Giannakopoulos and S.B. Buckley, "Sustainability of Open Distance eLearning institutions as knowledge producers: A theoretical perspective." Presented at 15th European Conference on Knowledge Management - ECKM 2014.- Polytechnic Institute of Santarém, Santarém, Portugal 4-5 September 2014.

[14] A. Giannakopoulos and S.B. Buckley, "The role of the educator in an open distance learning environment in the 21st century: Human versus machine? A pragmatic approach." Presented at 15th Annual conference on World Wide Web applications. CPUT, Cape Town, South Africa, 11-13 September 2013.

[15] Brundtland Commission. "Sustainable development." Available: http://en.m.wikipedia.org/Brundtland. Commission. 1987.

[16] G. Ergazakis, P. Metaxiotis and G. Psarras, "Knowledge cities: the answer to the needs of knowledge-based development." Journal of Knowledge Management, vol 36, no. 1, pp 67-84. 2006. https://doi.org/10.1108/03055720610667381

[17] A. Wiek, L. Withycombe and C.L. Redman, "Key competencies in sustainability: a reference framework for academic program development", Sustainability Science, vol. 6, no. 2, pp. 203-218. 2011 https://doi.org/10.1007/s11625-011-0132-6

[18] G. Rumble "Re-inventing Distance Education, 1971-2001." International Journal of Lifelong Education, Taylor \& Francis. 2001.

[19] DHET (Department of Higher Education and Training). (White paper for [post-school Education and Training]). "Building and expanded, effective and integrated post-school system." RSA. 2013

[20] C. Pienaar and C. Bester, "Addressing career obstacles within higher education environment: perspectives of academics." South African Journal of Psychology, vol 39, no. 3, pp 276-285. 2009 https://doi.org/10.1177/008124630903900311.

[21] P.J. Smith, Editorial. "Distance education: Past contributions and possible futures." Education, vol. 26, pp. 159-163. doi:http://dx.doi.org/10.1080/01587910500168819. 2005. https://doi.org/10.1080/01587910500168819

[22] J. Lave and E. Wenger, Situated learning: Legitimate peripheral participation, Cambridge: Cambridge University Press. 1991. https://doi.org/10.1017/CBO9780511815355

[23] E. Wenger and W.M. Snyder, "Communities of practice: The organizational frontier." Harvard Business Review, pp. 139-145. January/ February, 2000.

[24] E. Wenger, Communities of Practice: Learning Meaning and Identity, 6th ed. Cambridge University Press, Cambridge. 1998. https://doi.org/10.1017/CBO9780511803932

[25] K.S. Retna and P. Tee Ng, "Communities of practice: dynamics and success factors". Leadership \& Organization Development Journal, vol. 32, no. 1, pp.41-59, doi: 10.1108/01437731111099274. 2011. https://doi.org/10.1108/01437731111099274

[26] P. Akhavan, B. Marzieh and M. Mirjafari, "Identifying the success factors of Communities of Practice (CoPs): How do they affect on students to create knowledge?", VINE, vol. 45, no. 2, pp.198-213, doi: 10.1108/VINE-03-2014-00227. 2015.

[27] D. Boud and H. Middleton, "Learning from others at work: communities of practice and informal learning', Journal of Workplace Learning, vol. 15 , no. 5, pp. 194-202. 2013. https://doi.org/10.1108/13665620310483895

[28] L. Vygotsky, Mind and society: The development of higher psychological processes. Cambridge, University press. doi:10.1017/CBO9780511803932; 1978. https://doi.org/10.1017/CBO9780511803932

[29] C. Fearon, H. McLaughlin and T. Yoke Eng, "Using student group work in higher education to emulate professional communities of practice", Education + Training, vol. 54, no. 2/3, pp.114-125, doi: 10.1108/00400911211210233. 2012. https://doi.org/10.1108/00400911211210233

[30] S. Pavlin, "Community of practice in a small research institute". Journal of Knowledge Management, Vol. 10 Issue: 4, pp.136-144, doi: 10.1108/13673270610679426. 2006 https://doi.org/10.1108/13673270610679426.

[31] K. Kasemsap, "Utilizing Comunities of Practice to facilitate knowledge sharing in the digital age." in Organizational knowledge facilitation through Communities of Practice in Emerging Markets, S.B. Buckley, G. Majewski and A. Giannakopoulos, Eds, .pp. 198-225. Hearshy, PA: IGI Global, 2016, pp 198-225. https://doi.org/10.4018/978-1-5225-0013-1.ch011

[32] C. H. Monaghan and N.I. Columbaro, "Communities of practice and students' professional development." International Journal of Teaching and Learning in Higher Education, vol. 20, pp.413-424. 2009.

[33] NRF (National Research Foundation), Communities of Practice. . SARChI, South Africa, January 2017

[34] A. Ardichvili, V. Page and T. Wentling, "Motivation and barriers to participation in virtual knowledge-sharing communities of practice." Journal of Knowledge Management, vol. 7, no. 1, pp.64-77, doi: 10.1108/13673270310463626. 2003 https://doi.org/10.1108/13673270310463626

[35] E.C. Cheng and J.C. Lee, "Developing strategies for communities of practice." International Journal of Educational Management, vol. 6, pp. 751-764. doi: 10.1108/IJEM-07-2013-0105. 2014. https://doi.org/10.1108/IJEM-07-2013-0105

[36] E. Wenger, R.A. McDermott and W. Snyder, Cultivating Communities of Practice: A Guide to Managing Knowledge. Harvard Business School Press, Boston, MA. 2002.

[37] J. Tummons, "Learning architectures and communities of practice in higher education." in Theory and Method in Higher Education Research II (International Perspectives on Higher Education Research, Volume 10), J. Huisman , M. Tight (ed.). Emerald Group Publishing . 2014.

[38] M. Fontaine, "Keeping CoP afloat: understanding and fostering roles in communities." Knowledge Management Review, vol. 4, no. 4, pp. 16-21. 2001.

[39] J.E. Strydom, M. Mentz and G.D. Kuh, "Enhancing Success in Higher Education by Measuring Student Engagement in South Africa." Available:

http://sasse.ufs.ac.za/dl/userfiles/documents/SASSEinpresspaper_1.pdf.. 2009.

[40] J.E. Strydom and M. Mentz, "Focusing the Student Experience on Success through Student Engagement." Council on Higher Education, Pretoria, South Africa. 2010.

[41] A. Giannakopoulos, "How Critical Thinking, Problem-solving and Mathematics Content Knowledge Contribute to Vocational Students' Performance at Tertiary Level: Identifying Their Journeys." $\mathrm{PhD}$. dissertation, Dept. Education., University of Johannesburg., Johannesburg, RSA, 2012. 